Spatial Demography 2013 1(2): 162-177

http://spatialdemography.org

OPEN ACCESS

via Creative Commons 3.0
ISSN 2164-7070 (online)

RESEARCH

\title{
Poverty Segregation in Nonmetro Counties: A Spatial Exploration of Segregation Patterns in the US
}

\author{
P. Johnelle Sparksa, Corey S. Sparksa and Joseph J.A. Campbellb \\ a The University of Texas at San Antonio \\ b United States Automobile Association
}

\begin{abstract}
Most research on segregation focuses on racial residential segregation in metropolitan statistical areas and typically uses a-spatial measures of segregation. What is less clear is if segregation measures operate in a similar fashion in nonmetropolitan areas and if spatial patterns exist for poverty segregation in nonmetro counties. The purpose of this research was to examine multiple dimensions of poverty segregation in the United States the period 2006-2010 for metropolitan and nonmetropolitan counties. Data for this analysis come from the 2006-2010 American Community Survey 5 year estimates, the 2000 U.S. Census of Population and Housing, Summary File 3 and the USDA Economic Research Service. Four different measures of poverty segregation were calculated, including both aspatial and spatial measures. A nonparametric Kruskal-Wallis test was used to test for variation in the segregation indices across metro and nonmetro areas and spatially autoregressive models were used to examine the socioeconomic correlates of poverty segregation. Results indicate significant variation in poverty segregation patterns in metro and nonmetro counties in the US, and nonmetro counties outside of the South have significantly lower levels of poverty segregation. This research adds to the literature by exploring patterns of metro and nonmetro poverty segregation and measuring different dimensions of segregation with an explicit spatial referent across counties in the contiguous United States in an effort to note differences in how segregation works across rural and urban places.
\end{abstract}

KEYWORDS: Poverty segregation, metro/nonmetro, spatial regression

\section{INTRODUCTION}

One of the basic premises underlying most measures of residential segregation is the inherent spatial patterning of different groups in

Corresponding Author: P. Johnelle Sparks, Ph.D.

Associate Professor, Department of Demography, The University of Texas at San Antonio, 501 West Durango Street, San Antonio, Texas 78207

Tel: +1 (210)458-3141

Email: johnelle.sparks@utsa.edu an urban environment (Cortese, Falk, \& Cohen, 1976; Duncan \& Duncan, 1955; D.S. Massey \& Denton, 1988; D. S. Massey, White, \& Phua, 1996). The majority of research exploring residential segregation and its potential impact on a variety of health, education, employment, inequality, crime, and other outcomes has focused on metropolitan areas as the unit of analysis, often defined as metropolitan statistical areas (MSAs) or labor market areas (Brown \& Chung, 2006; Fischer, Stockmayer, Stiles, \& Hout, 2004; Frey \& Farley, 1996; Logan, Alba, \& 
Zhang, 2002; Logan, Stults, \& Farley, 2004; Douglas S. Massey, 1996; Wilkes \& Iceland, 2004). However, recent work highlights the importance of considering segregation patterns in nonmetropolitan areas as well. In one of the few national studies available on the topic, Lichter and colleagues (D. T. Lichter, Parisi, Grice, \& Taquino, 2007) explore racial residential segregation patterns for rural areas and small town in the US from 1990 to 2000. One of the most important findings from this research was that similar racial residential segregation patterns and trends were observed over this period between both metropolitan and nonmetropolitan areas. In another study, Lichter, Parisi, Taquino, and Beaulieu (2008) found that rural poverty was highly concentrated spatially and that poor residents were segregated from non-poor residents in rural areas, particularly among poor rural minorities.

With more attention now devoted to the study of spatial inequality (Lobao, Hooks, \& Tickamyer, 2007), it is important to identify why certain dimensions of segregation are spatially patterned and if these patterns have different correlates across metro and nonmetro locations. Individuals make decisions about where they want to live relative to resources (i.e., schools, employment, health care, environment, amenities) available in an area (Iceland, Goyette, Nelson, \& Chan, 2010), and these decisions may differ for rural and urban residents. However, poor individuals in general can be less mobile and have fewer opportunities to live in wealthier neighborhoods, regardless of whether they live in a rural or inner-city urban environment. Further rural residents do not select to live in rural or remote areas because they are poor or vice versa (Partridge \& Rickman, 2008). Structural or place based arguments of poverty would argue that the spatial concentration of poor individuals in a local area is due to few economic opportunities and underinvestment in infrastructures (Tickamyer \& Duncan, 1990; Voss, Long, Hammer, \& Friedman, 2006). However little work has examined whether the spatial concentration of poverty in nonmetro areas is really a function of poverty segregation using a placed-based poverty argument and if a potential spatial mismatch exists to explain higher rural poverty and poverty segregation.

From a population perspective, the changing population composition of many rural areas and the blurring of rural and urban boundaries elevates the importance of studying segregation in nonmetro and metro areas, particularly the economic aspects of segregation. This research starts to fill this gap by using spatial regression methods to document poverty segregation patterns across the United States. Additionally we assess correlates of poverty segregation in metro and nonmetro counties by measuring multiple dimensions of segregation. More specifically this research asks two questions. First, how is poverty segregation spatially distributed in the US? And second, are the determinants of place-based poverty segregation in metropolitan and nonmetropolitan areas different and do these patterns differ by region?

\section{Spatial Mismatch in Nonmetro Poverty Segregation}

Poverty rates decreased significantly from 1990 to 2000 (P.A. Jargowsky, 2003), and nonmetro areas experienced more of a decline in poverty than metro areas (Jolliffe, 2004; D.T. Lichter \& Johnson, 2007). Yet even with declines in poverty rates over this period, the spatial concentration of poverty remained high for many areas in the US (Foulkes \& Schafft, 2010; P.A. Jargowsky, 2003). Rural poverty has been shown to be more highly concentrated spatially than urban poverty (D.T. Lichter, et al., 2008), however patterns of metro and nonmetro poverty concentration differ based on the scale at which poverty is assessed (D.T. Lichter \& Johnson, 2007).

Borrowing from the urban spatial mismatch literature, Partridge and Rickman (2008) argue that the location of rural populations relative to labor markets in more urban or suburban areas creates a distance based friction that may lead to higher rural poverty. Frictions are created when rural households are too far removed from labor markets that would allow residents of rural areas to maximize their employment opportunities and earn a wage to support their family. These 
authors also argue that the further a rural area is from a metro center that offers diverse employment opportunities, the more likely this rural area is to be poor. However this pattern may differ across areas of the US as certain nonmetro areas have different contact and exposure to urban areas that facilitate more "interdependence" between rural and urban places both socially and economically (D.T. Lichter \& Brown, 2011).

Commuting and migration barriers relative to labor markets creates the potential for a rural spatial mismatch and higher rural poverty (Blumenberg \& Shiki, 2004). Transportation barriers create commuting problems for rural residents (Beale, 2004), making the possibility of traveling to another area for work more difficulty and costly. Therefore rural residents may have excess labor supply or underemployment in their local areas, which can translate to lower levels of employment or high unemployment and high rates of poverty (Partridge \& Rickman, 2008). Additionally rural residents may enjoy the amenities present in their local area and depend on family and close social networks to assist each other during difficult economic times making the possibility of migration to an area with more employment opportunities less likely. Therefore non-monetary costs associated with transportation or migration create a distance based friction or spatial mismatch for rural areas. Ultimately this spatial mismatch could result in more poverty segregation for nonmetro residents if economic opportunities are limited in the local areas for low-income residents, while highincome residents of nonmetro areas depend on the fluidity of boundaries between suburban and urban areas to enhance their economic opportunities. This spatial mismatch would further concentrate poverty segregation in nonmetro areas.

Uneven regional development and economic restructuring presents unique barriers to developing the economic base of many rural areas as well (Bryden \& Bollman, 2000; Lobao, et al., 2007; MacKay, 2003). These changes raise the importance of examining structural determinants of area poverty (D.T. Lichter, et al., 2008) and the patterns of poverty segregation that emerge as the result of labor market mismatches across diverse rural areas of the United States. Wage and salary differentials remain large between industries in rural and urban areas, with rural residents receiving less compensation in similar industries compared to their urban counterparts (Vias, 2012). In addition, it is the lower skilled workforce and less mobile population of rural areas that often face reduced employment opportunities due to changes in local economic sectors (MacKay, 2003). Yet is not poverty alone that places rural residents at a disadvantage. While poverty is more spatially concentrated in rural areas (Voss, et al., 2006), poor rural residents face additional barriers including physical isolation, limited access to public transportation, lower access to high quality schools, and lower access to services (medical, utilities, grocery stores, etc.) (Jensen, McLaughlin, \& Slack, 2003). Changes to local and regional economies makes it necessary to understand how poverty operates over space in order to offer sound structural policies to address the presence of nonmetro poverty segregation and potential spatial mismatch in how poverty segregation is concentrated in nonmetro areas.

\section{DATA \& METHODS}

Data for this analysis come from three sources: the 2006-2010 American Community Survey 5 year estimates, the 2000 U.S. Census of Population and Housing, Summary File 3 and the USDA Economic Research Service (ERS) county typology codes for 2004. Patterns of residential poverty segregation were considered for all counties in the contiguous United States. For all segregation measures, each index was based on tract data within each county, which has been argued to be a better unit of analysis for detecting variation in segregation patterns across areal units (Lichter et al. 2007; Reardon and O'Sullivan 2004).

Massey and Denton (1988) outline evenness, exposure, concentration, centralization, and clustering as five dimensions of residential segregation. We measure poverty segregation 
using four indexes including: the dissimilarity index $(D)$ to measure evenness, the interaction index $\left({ }_{x} P_{y}{ }^{*}\right)$ to measure exposure, and the spatial proximity index to measure clustering (Massey and Denton 1988; Reardon 2006). These measures were selected since they compare two subgroups to each other when calculating the segregation measure instead of considering one group by itself. The four measures used here capture poverty segregation, where poverty is defined as the number of persons living below the federally designated poverty threshold in each block group. Measures for four of these dimensions (evenness, exposure, and clustering) were utilized to: 1) investigate the differences in residential segregation among metropolitan and nonmetropolitan areas of the United States, and 2) determine if any of the segregation measures offers support for a poverty segregation spatial mismatch in nonmetro areas.

The index of dissimilarity, the most widely used measure of residential evenness, measures the invariability of the distribution between two groups across a county. The dissimilarity index can be interpreted as the proportion of residents living below the poverty threshold that would have to move to a different block group in the county in order to produce an even distribution with those residents living above the poverty threshold. One formula for the index of dissimilarity is:

$$
D=\frac{1}{2} \sum_{i=1}^{n}\left|\frac{x_{i}}{X}-\frac{y_{i}}{Y}\right|
$$

where $x_{i}$ is the number of residents in the $i$ th block group in a county living below the poverty threshold, $X$ is the total number of county residents living below the poverty threshold, $y_{i}$ is the number of residents in the ith block group living above the poverty threshold, and $Y$ is the total number of county residents living above the poverty threshold. This index varies between o.o and 1.o, with 0.0 corresponding to perfect integration between residents living above and below poverty and 1.0 corresponding to perfect segregation. A dissimilarity index score of 1 would therefore be interpreted as 100 percent of residents in a county living below the poverty threshold would need to change their block of residence in the county in order to achieve an even poverty distribution.

Residential exposure refers to the possibility of interaction between residents living below the poverty threshold and residents living above the poverty threshold within a county. Indexes of exposure measure the extent to which poor and non-poor residents come into contact with one another simply by sharing a common residential area. The interaction index, a basic measure of residential exposure, measures the extent to which residents living below the poverty threshold are exposed to residents living above the poverty threshold. It has been denoted as ${ }_{x} P_{y}{ }^{*}$ by Lieberson (1981):

$$
{ }_{x} P_{y}^{*}=\sum_{i=1}^{n}\left[\frac{x_{i}}{X} \frac{y_{i}}{t_{i}}\right]
$$

where $x_{i}, y_{i}$, and $t_{i}$ are the number of residents living below the poverty threshold, the number of residents living above the poverty threshold, and the total population of block group $i$ within a county, respectively. $X$ represents the total number of residents living below the poverty threshold in the county. The index varies between 0.0 and 1.0 and can be interpreted as the probability a resident living below the poverty threshold shares an area with a resident living above the poverty threshold.

Spatial clustering refers to the extent to which population subgroups live next to other groups or cluster in space. The index of spatial proximity is adapted from White (1986) to measure the clustering of economic subgroups in space. To adequately calculate the spatial proximity index, the average proximity between members of the same group must first be calculated. The average proximity between members of an arbitrary group $Z$ can by approximated by:

$$
P_{x x}=\sum_{i=1}^{n} \sum_{j=1}^{n} \frac{z_{i} z_{j} c_{i j}}{Z^{2}}
$$


where $c_{i j}$ is a dichotomous variable with a value of one indicating block group $i$ is continuous to block group $j$ and zero otherwise, $z_{i}$ is the subgroup population of the $i$ th block group in a county, $z_{j}$ is the subgroup population of the $j$ th block group in a county, and $Z$ is the total subgroup population of the county. The index of spatial proximity is simply the average of the intragroup proximities weighted by the fraction of each group in the population:

$$
S P=\frac{X P_{x x}+Y P_{y y}}{T P_{t t}}
$$

where $P_{x x}, P_{y y}$ and $P_{t t}$ are the average proximity between residents living below the poverty threshold, the average proximity between residents living above the poverty threshold, and the average proximity between for the total population, respectively. $X$ is the total number of residents living below the poverty threshold in the county, $Y$ is the total number of residents living above the poverty threshold in the county, and $T$ is the total population of the county. If there is no differential clustering between residents living below the poverty threshold and residents living above the poverty threshold, the spatial proximity index has a value equal to 1.0; it is greater than 1.0 when members of each group live nearer to one another than to members of the other group. The ratio would be less than 1.0 in the event that residents living below the poverty threshold and residents living above the poverty threshold reside closer to each other than to members of their own group.

Lastly, a measure of income inequality that does not dichotomize the poverty/non-poverty status is used. The index used is the Generalized Neighborhood Sorting Index (GNSI) (P. A. Jargowsky \& Kim, 2005), which extends the Neighborhood Sorting Index (NSI) (P. A. Jargowsky, 1996; P. A. Jargowsky \& Kim, 2005) by incorporating the spatial relationships between areas within a larger geographic area. Originally the GNSI was designed for use with household data, where household incomes were compared to the average income for their metro area, but here it is used with tracts and counties. The GNSI is calculated as:

$$
G N S I_{k}=\left(\frac{\sum_{i}^{n} h_{n}\left(m_{k n}-M\right)^{2}}{\sum_{i}^{n}\left(y_{i}-M\right)^{2}}\right)=\left(\frac{y^{\prime} W_{k}^{\prime} W_{k} y}{y^{\prime} y}\right)^{0.5}
$$

where $h_{n}$ is the number of household in the tract, $m_{k n}$ is the average income in the $\mathrm{k}^{\text {th }}$ neighborhood around tract $n, M$ is the mean income for the neighborhood which each tract is located, and $y_{i}$ is the average income for each tract. This equation can be more succinctly stated in matrix terminology, where $y$ is the deviation of each tract's average income from the county's average income, and $W_{k}$ is the row-standardized spatial weight matrix for all tracts. The index is bound on 0 and 1 . If the index takes the value 0 , then all spatial neighborhood mean incomes are the same as the county mean income, and a value of 1 indicates that all tracts are distinct and homogenous and have incomes equal to their spatial neighbors.

The goal of this analysis was to examine the determinants of these four dimensions of economic segregation and to examine a potential spatial mismatch in nonmetro poverty segregation. Regression models (described below) were estimated to examine the effects of rurality, county economic sectors, racial minority concentration, and persistent poverty on poverty segregation. However, since ecological analyses such as this are often problematic because both the outcomes and the predictors are measured at one time, true associations are difficult to tease apart. To overcome this, the outcome for this analysis is measured using the 2006-2010 American Community Survey, and all of the predictors are measured using the 2000 Summary File 3. This should allow for a more powerful design in the statistical analysis.

Racial concentration was measured by the proportion of the county population that was black in 2000. Similarly, the proportion of the 
county population that was Hispanic in 2000 was also included as a measure of racial concentration. The proportion of the county population over the age of 65 and the proportion of the county population who moved into the county within past 5 years were two additional variables included in the models that have been linked to economic segregation and poverty concentration. Controls for the geographic characteristics of the counties were also included in the models. The regional divisions used by the United States Census Bureau were included as factors in the model with the "South" region retained as a reference; thus, the change in economic segregation levels for the other three regions of the U.S. (Northeast, Midwest, and West) was compared to the South. The economicdependence in a county serves as another set of indicator variables included from the Economic Research Service (ERS). These indicators denote the primary means of employment and economic earnings for each U.S. county, and the following economic-dependence categories are identified: farming, mining, manufacturing, federal/state government, services, or nonspecialized. For this analysis, manufacturing-dependent counties were considered the reference group. As such, measured coefficients for the other five economic-dependence indicators along with their interpreted segregation level changes will be compared to manufacturing-dependent countylevel segregation. Additional predictors were used to control for variation in county level measures of education, unemployment and social service use. The percentage of the population 25 years of age and older with a college or professional degree captures the education level of each county. County unemployment was measured as the percentage of residents out of work or looking for work among those county residents of working ages. Social service use patterns were measured with three variables: the percentage of households receiving Supplemental Security income, the percentage of households receiving any public assistance income, and the percentage of households receiving Social Security income.

Other indicator variables included in the models were a measure of persistent poverty, the percentage of the workforce working elsewhere, and county metropolitan status. Counties were considered persistently poor if the proportion of the population living in poverty over the last 30 years (measured by the 1970, 1980, 1990 and 2000 decennial censuses) was 20 percent or more. The percentage of workers working elsewhere was taken from the census and represents the proportion of workers over age sixteen that worked in a county other than the one in which they reside. The nonmetropolitan classification for each county was taken directly from the resources available from ERS as both a dichotomous measure and as a classification measure based on the rural-urban continuum codes. To estimate the effects of these predictors on the four segregation measures, two regressionbased methodologies were used. First, a basic Kruskal-Wallis test was used to examine variation in the four segregation indices across the ten levels of the rural-urban continuum codes. The second analytical methodology used was the spatially autoregressive model. This model was used to examine the relationships between the segregation indices and the predictors while accounting for spatial structure in the data. An interaction specification model was examined. The interactions specified were between the nonmetro status dummy variable and the regional dummy variables. This was done to examine potential differences in poverty segregation between metro and nonmetro counties in different regions of the country. For each outcome, alternative specifications of the SAR model were compared using Lagrange multiplier specification tests on OLS models(Anselin, 2002a; Anselin \& Bera, 1998). Two model specifications are considered: the spatial error and spatial lag models. First, the spatial error model is considered, which is defined by adding a spatial structure term to the OLS model's residuals, $\varepsilon$ :

$$
\begin{aligned}
& y=X^{\prime} \beta+\varepsilon \\
& \varepsilon=\rho W e+u
\end{aligned}
$$

This model specification essentially says that all autocorrelation is confined to the error term in the model, which can be written in two parts: the spatially structured residual, e, and the random residual, $\mathrm{u}$, which are random and 
homoskedastic. The cause of such residual autocorrelation is typically thought to arise from the exclusion of an unobserved endogenous spatially structured covariate that, were it measurable, would explain the spatial autocorrelation in the residuals. The parameter $\rho$ measures the strength of the autoregressive effect on the model residuals amongst neighboring observations (Anselin, 2002a; Anselin \& Bera, 1998; Chi \& Zhu, 2008). In essence, the weight matrix accounts for the total number of neighbors that a county has, and it assigns a value of 1 whenever two counties are neighbors, and 0 otherwise (Anselin, 2002b; Bivand, et al., 2011). By row-standardizing the matrix, each row sums to one, which removes effects of counties with a large number of neighbors (Tiefelsdorf \& Griffith, 1999).

The second spatial regression model specification is the spatial lag model, specified as:

$$
y=\rho W y+X^{\prime} \beta+\varepsilon
$$

where the spatial component $(\rho W y)$ is specified on the model intercept. In doing so, the model's intercept is lagged across neighbors. This model specifies the spatial effects as a diffusion process, where neighboring county values of segregation influence the values of other counties that border them.

The choice of spatial weighting scheme is important in such analyses, and two different neighbor types are considered: these are contiguity and distance based neighbors. To measure contiguity based neighbors, a Queen rule is used, and to measure distance based neighbors, a k-nearest neighbor weighting scheme is used, with alternative values of $\mathrm{k}$ from 2 to 6 . The weighting scheme was chosen for each outcome so that the spatial dependence in the outcome was maximized (Chi \& Zhu, 2008). All model estimation was done in R 2.15.1 (R Development Core Team, 2012).

\section{RESULTS}

Descriptive statistics for the segregation indices and the predictor variables are presented in Table 1.
In addition, maps of the four segregation measures are presented in Figure 1.

The dissimilarity index shows that almost $19 \%$ of US county residents would have to move to a different tract group in the county in order to produce an even distribution of residents living above the poverty threshold. Figure 1 shows that high values of the dissimilarity index are concentrated in the Northeastern seaboard, Midwest and Southwest, with various pockets of high clustering surrounding metropolitan areas in the South. The interaction index has an average value of 0.81 , suggesting a relatively high probability of a resident of a county living in poverty running into a resident not it poverty. Figure 1 shows the highest values of this index occur in Midwestern counties and in Northern Virginia, and the lowest values typically occur in Appalachia, the South and Southwest. The spatial proximity index shows about the same general spatial clustering as the first two segregation measures, and its mean of 0.94 suggests that on average people above and below the poverty line live in closer proximity to one another. The GNSI shows a higher degree of spatial clustering, with higher values in Florida, the northeast and the west, and metro areas of the South. All of these measures show significant values of Moran's I, which suggests some average clustering among neighboring counties across the US, although the values of the statistic are not high. While these spatial displays are instructive to the nature of the spatial clustering of these indices, when these indices are compared across the categories of the rural-urban continuum codes (RUCC), other trends are apparent.

Figure 2 shows box and whisker plots of the distribution of the four indices by the rural-urban continuum code (RUCC) classification scheme, in which higher values of the RUCC are more rural and lower values more urban/metropolitan. The dissimilarity index shows a strong negative association across these codes, with larger metropolitan areas showing higher values of the dissimilarity index, suggesting more segregation, while in more rural areas segregation is not as prevalent. There is significant variation in the poverty dissimilarity index across these codes 
Table 1. Descriptive Statistics for Poverty Segregation Measures and Predictors

\begin{tabular}{|c|c|c|c|}
\hline Variable & Mean or Proportion & Std.* & Moran's I** \\
\hline \multicolumn{4}{|l|}{ Dependent Variables } \\
\hline Dissimilarity Index & 0.186 & 0.107 & 0.304 \\
\hline Interaction Index & 0.812 & 0.091 & 0.276 \\
\hline Spatial Proximity Index & 0.935 & 0.252 & 0.285 \\
\hline GNSI & 0.324 & 0.244 & 0.414 \\
\hline \multicolumn{4}{|l|}{ Sociodemographic Variables } \\
\hline Nonmetro Status (Nonmetro $=1$ ) & 0.727 & - & 0.418 \\
\hline \% Black & 0.088 & 0.146 & 0.792 \\
\hline \%Hispanic & 0.061 & 0.121 & 0.812 \\
\hline$\%$ Aged $65+$ & 0.146 & 0.044 & 0.513 \\
\hline \% Population Moved Last 5 Years & 0.213 & 0.073 & 0.426 \\
\hline \multicolumn{4}{|l|}{ Economic Dependence Variables } \\
\hline Manufacturing & 0.285 & - & 0.308 \\
\hline Farming & 0.142 & - & 0.407 \\
\hline Federal/State Government & 0.114 & - & 0.096 \\
\hline Mining & 0.04 & - & 0.288 \\
\hline Service & 0.107 & - & 0.227 \\
\hline Nonspecialized & 0.299 & - & 0.111 \\
\hline Persistent Poverty & 0.123 & - & 0.468 \\
\hline $\begin{array}{l}\text { \% of Workers Not Working in } \\
\text { County }\end{array}$ & 0.329 & 0.178 & 0.249 \\
\hline \multicolumn{4}{|l|}{ Regional Variables } \\
\hline South & 0.445 & - & - \\
\hline Northeast & 0.07 & - & - \\
\hline Midwest & 0.339 & - & - \\
\hline West & 0.133 & - & - \\
\hline \multicolumn{4}{|l|}{ Other Predictors } \\
\hline Mean Size of Block Group $\left(\mathrm{mi}^{2}\right)$ & 82.17 & 185.4 & 0.481 \\
\hline $\begin{array}{l}\% \text { of Population Age } 25+\text { with } \\
\text { College Degree }\end{array}$ & 0.018 & 0.0123 & 0.288 \\
\hline \% Unemployed & 0.058 & 0.027 & 0.422 \\
\hline \% of Households Receiving SSI & 0.051 & 0.027 & 0.683 \\
\hline $\begin{array}{c}\% \text { of Households Receiving Public } \\
\text { Assistance Income }\end{array}$ & 0.033 & 0.019 & 0.439 \\
\hline $\begin{array}{l}\text { \% of Households Receiving Social } \\
\text { Security Income }\end{array}$ & 0.306 & 0.063 & 0.496 \\
\hline
\end{tabular}

*No standard deviations for proportions are reported.

**All values of Moran's I are significantly different from zero using a Monte Carlo hypothesis test at $\alpha=.001$. No Moran's I values are reported for the regional indicator variables, as these will of course have spatial structure. 

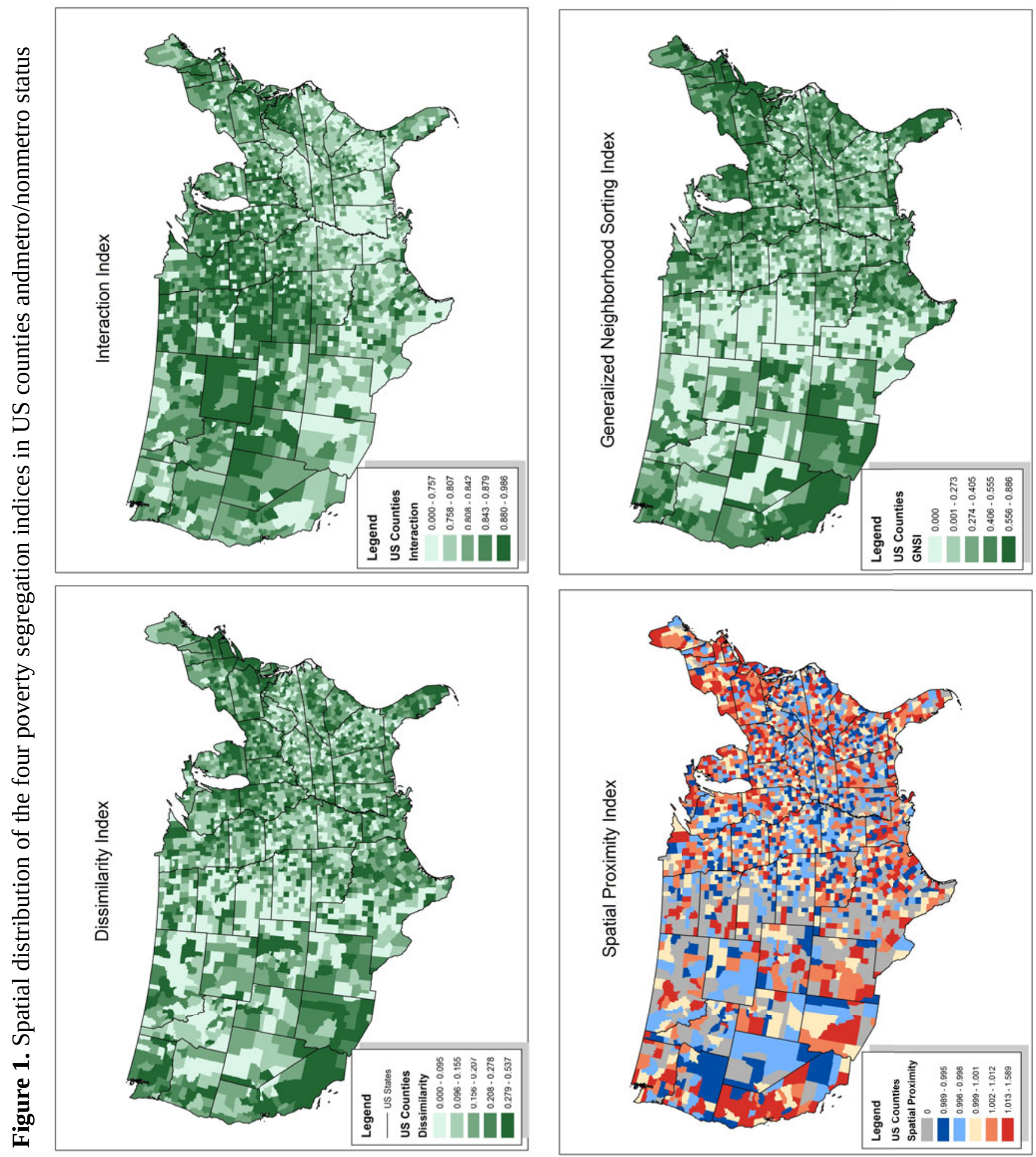
Figure 2. Distributions of Dissimilarity index, Interaction Index, Spatial Proximity Index and Generalized Neighborhood sorting index by Continuum Code.
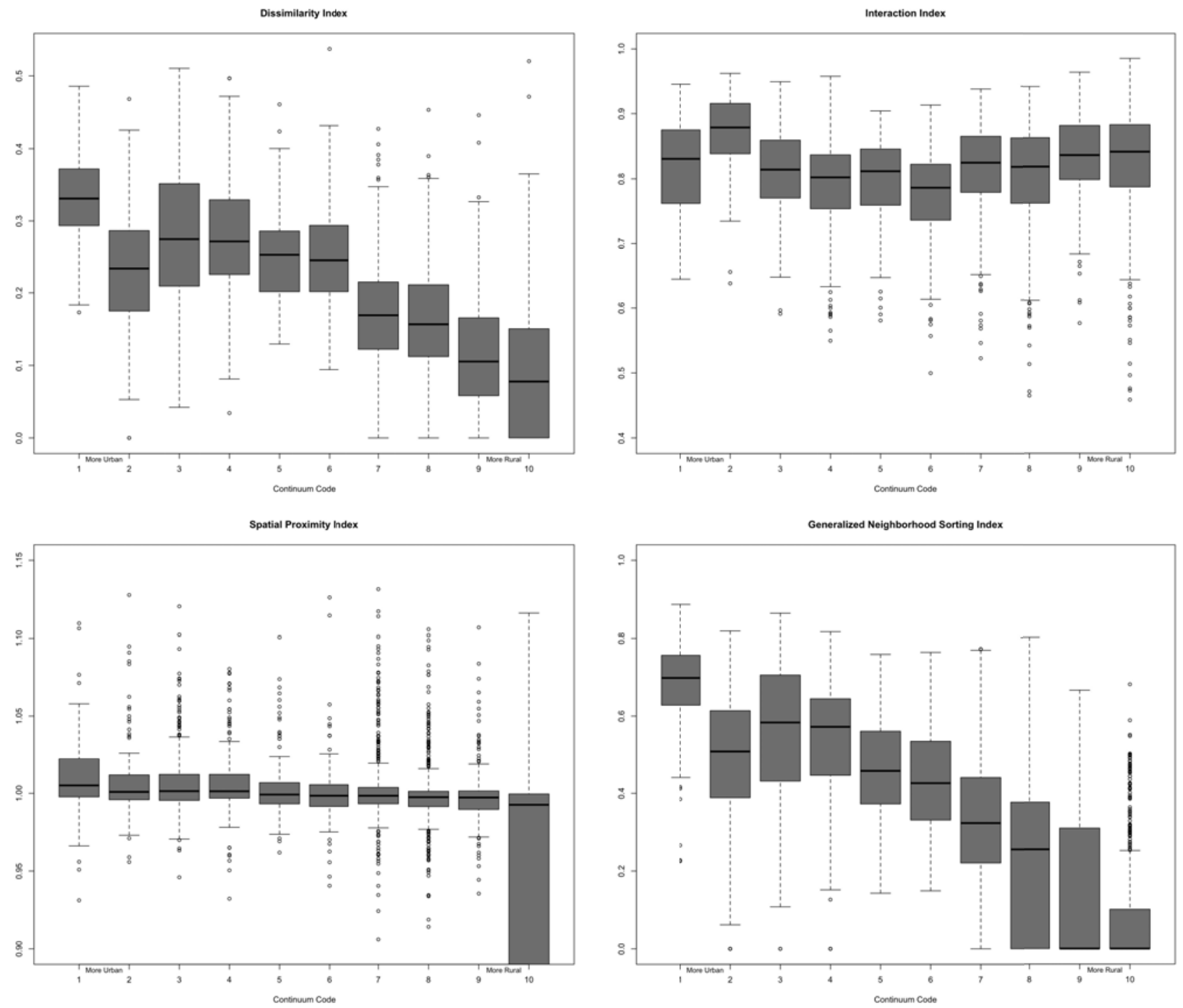

using the Kruskal-Wallis test $\left(\chi^{2}=1,389, \mathrm{df}=9\right.$, $\mathrm{p}=<0.0001)$. The poverty interaction index shows a generally flat trend across the ruralurban continuum, suggesting that on average, the index is high in all types of counties. Of the four poverty segregation measures, the poverty interaction index witnesses the highest values across the different types of nonmetro counties. However, in general the value for this measure is higher across all counties compared to the patterns for the other segregation measures.

Despite the flatness of the trend, there is significant variation across these codes using the Kruskal-Wallis test $\left(\chi^{2}=202, \mathrm{df}=9, \mathrm{p}=<0.0001\right)$. The spatial proximity index shows patterns very similar to those of the dissimilarity index: higher values are observed in metropolitan areas $(>1$, suggesting higher levels segregation) while lower values are observed in nonmetro areas $(<1$, suggesting lower levels segregation). There is significant variation across these codes using the Kruskal-Wallis test $\left(\mathrm{x}^{2}=1,261, \mathrm{df}=8, \mathrm{p}=<0.0001\right)$. 


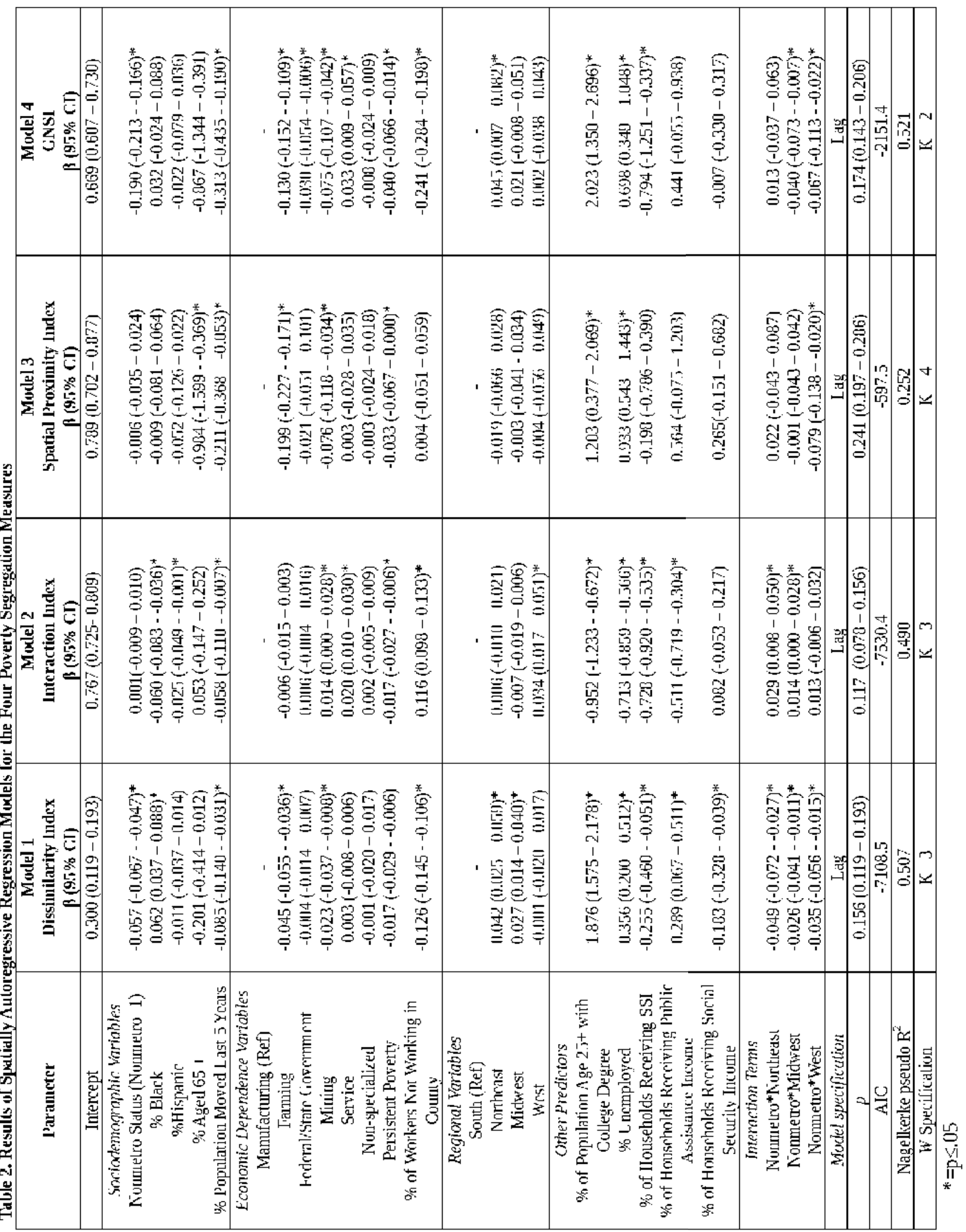


The GNSI shows a nearly identical, if not stronger negative trend, as the dissimilarity index across the rural urban continuum, with the more rural areas showing lower levels of income segregation than more metro areas. These results document that the level of segregation varies between different types of metro and nonmetro counties, and that the trends are in general in the direction of less segregation in nonmetro areas, except for the interaction index.

Next, the results of the spatial regression models are discussed. Robust Lagrange multiplier tests showed that each outcome was best modeled as a lag process, although the neighbor specifications varied between outcomes. Table 2 presents the results of the spatially autoregressive models.

These models estimate the strength of the association between the dependent variable in neighboring counties using the parameter $\rho$. As these models are not fit with least squares, but with maximum likelihood, no real $\mathrm{R}^{2}$ values are available, but Nagelkerke pseudo $\mathrm{R}^{2}$ values are reported.

Model 1 in Table 2, uses the poverty dissimilarity index as the outcome. As seen in the boxplot, there is a significant negative association between dissimilarity and metro status, with nonmetro counties having lower levels of segregation. The proportion of the county population that is black is a significant predictor of poverty dissimilarity, suggesting that, once the spatial structure of the data is accounted for, counties with higher proportions of black residents have higher levels of poverty segregation. Also, the proportion of the population that moved into the county in the last five years is also significant in Model 1, which indicates that counties experiencing more population turnover experience lower poverty segregation. Three economic sector variables show significant association with the dissimilarity index: higher levels of farming, mining and workers leaving the county for work are all associated with lower levels of segregation. Counties with higher proportions of residents with some college education or more, higher levels of unemployment and higher levels of public assistance have higher values of poverty dissimilarity, while counties with higher proportions of household receiving SSI have lower levels of segregation. A significant regional interaction is found for nonmetro counties in the Northeast, Midwest and West, where nonmetro counties in these regions witness lower levels of poverty segregation than metro counties in the South.

Model 2 considers the interaction index as the outcome variable. Counties with higher proportions of black or Hispanic residents have lower levels of interaction, as do counties with higher proportions of movers. With respect to the economic variables, counties with higher levels of the workforce in mining and services and that have higher proportions of their workforce working outside of the county have higher levels of poverty interaction. Counties that have been persistently poor for thirty years show lower levels of poverty interaction. Counties with a more highly educated population and with higher proportions of unemployed workers and households receiving SSI or public assistance have lower levels of poverty interaction. Finally, nonmetro counties in the Northeast and Midwest have higher levels of poverty interaction than metro areas of the South.

Model 3 consider the spatial proximity index as the outcome variable. While no race/ethnicity effects are noted, counties with higher proportions of the population over age 65 and counties with a more mobile population show lower levels of segregation between poor and non-poor residents. Three economic variable show significant associations: counties with higher proportions of the labor force in farming and mining and those that have been persistently below the poverty line show lower levels of poverty segregation. Counties with more educated populations and counties with higher levels of unemployment both show higher values of segregation. Finally, nonmetro counties in the West region show lower levels of segregation than metro areas of the South.

Model 4 considers the GNSI as the dependent variable. Again, as seen in Figure 2, the index shows lower values in nonmetro areas and in 
areas with more a higher proportion of movers. Counties with higher proportions of the workforce in farming, federal or state government or mining show lower levels of the index, while counties with more service-centered economies show higher values; also counties that are considered persistently poor show lower levels of the index. Counties with more educated populations and with higher levels of unemployment both show higher values of the index, while counties with higher proportions of households receiving SSI income have lower values. Finally, nonmetro counties in the Midwest and West regions show lower levels of the index than metro areas of the South.

\section{DISCUSSION}

Significant spatial patterns of poverty segregation were observed for all four measures in this analysis. Clear regional differences were also noted for each of these measures of poverty segregation. However, the degree of segregation was found to differ across metro and nonmetro counties in the bivariate analyses shown in Figure 2 (and tested by the Kruskal-Wallis test), with nonmetro counties experiencing lower levels of poverty segregation than the most metro counties. This pattern is particularly evident for the dissimilarity, spatial proximity and GNSI indexes. Less variation is noted between the level of poverty segregation based on the interaction index between metro and nonmetro counties, even though statistically significant differences are noted across county designations.

The low variation in the spatial proximity index across different nonmetro counties presents an interesting finding about the potential interaction between poor and non-poor residents of nonmetro counties. While the mean value for this index across the most metro counties had a value of 1 , indicating that poor and non-poor residents are spatially mixed, the small variation in these values may be due to the larger tract sizes in nonmetro counties making it more difficult to isolate distinct spatial patterns in nonmetro counties. Alternatively, values of poverty segregation measured by the spatial proximity index in nonmetro counties indicate that the poor are less spatially segregated from the non-poor, which was explored in more detail in the regression models used to assess the potential of a spatial mismatch in poverty segregation patterns in nonmetro counties in the US.

Nonmetro counties experienced lower levels of poverty segregation than metro counties on two of the four segregation measures in the spatial regression models. However, significant nonmetro regional effects were also noted in all of the models. In most instances, nonmetro counties in the West experienced different poverty segregation patterns than metro counties in the South. This finding deserves further attention since less variation in general was noted in the value of the interaction index in different types of nonmetro counties based on the bivariate tests. True regional variations are masked in this measure of poverty segregation without considering structural conditions and locations of counties. Blurring of metro-nonmetro boundaries across regions of the US raise questions about the role of segregation on nonmetro residents.

Some support exists for the potential spatial mismatch argument presented above, in that counties with larger proportions of residents traveling to other counties for employment experience lower levels of poverty segregation as measured by the dissimilarity, interaction and GNSI indexes. If people are able to secure employment outside of their local area, their chances of being poor are likely to decrease. Likewise a county's main form of economic dependence is associated with poverty segregation for all four measures, and most of these effects are consistent in their direction across models. Of each of the economic dependence categories, counties dependent on farming, mining and to a lesser degree government witness a protective effect against poverty segregation compared to counties dependent on services. Since rural areas have traditionally been more dependent on agriculture, mining, and manufacturing, the restructuring of service based industries in more metro areas may contribute to distance based friction and increased intensity of poverty 
segregation for certain nonmetro counties, particularly in the South. This finding deserves more exploration based on potential economic dependence nonmetro interactions and their impact on poverty segregation.

There were few effects noted of racial/ethnic population composition. A statistically significant association was observed between the percentage of the county population that was Hispanic and interaction, and a significant association between proportion black and the dissimilarity and interaction indices. For the dissimilarity and interaction indexes, lower levels of poverty segregation were observed for counties with higher proportions of the population that was Hispanic or black, while the opposite was true for blacks and the dissimilarity index. With increasing Hispanic migration into nonmetro areas (Johnson \& Lichter, 2010; Kandel, 2005; Kandel \& Cromartie, 2004), this association may indicate that nonmetro areas will not experience high levels of poverty segregation, with NonHispanics and Hispanics choosing different residential areas within these places. It will be important to document this finding over time as the Hispanic population continues to grow in less traditional nonmetro areas.

\section{LIMITATIONS}

As an aggregate analysis, there was also attention given to the interpretation of associations noted in the results, as to not make erroneous claims that make generalizations to individuals within counties.

Second, standard measures of residential segregation are based on the examination of residential patterns in metropolitan statistical areas (MSA) or central cities (Douglas S. Massey, 1996; D.S. Massey \& Denton, 1988; Douglas S. Massey \& Denton, 1989). In this paper, we constructed four measures of poverty segregation for all counties in the U.S. based on three different dimensions of segregation. It is not clear if the interpretation and application of residential segregation indices operate in the same way between metropolitan and nonmetropolitan locations in the United States. However, we feel confident in the associations noted in the spatial regression models, since we allow for potential metro/nonmetro interactions based on region, and these nonmetro-region interactions were statistically significant.

\section{References}

Anselin, L. (2002a). Under the hood: Issues in the specification and interpretation of spatial regression models. Agricultural Economics, 27, 247-267.

Anselin, L. (2002b). Under the Hood. Issues in the Specification and Interpretation of Spatial Regression Models. Retrieved from

https://geodacenter.asu.edu/pdf/hood.pdf

Anselin, L., \& Bera, A. K. (1998). Spatial dependence in linear regression models with an introduction to spatial econometrics. In A. Ullah \& D. E. A. Giles (Eds.), Handbook of Applied Economic Statistics (pp. 237-289). New York: Marcel Dekker.

Beale, C. L. (2004). Anatomy of nonmetro high poverty areas: common in plight distinctive in nature. Amber Waves, 2.

Bivand, R., Altman, M., Anselin, L., Assunção, R., Berke, O., Bernat, A., et al. (2011). spdep: Spatial dependence: weighting schemes, statistics and models. $\mathrm{R}$ package version $0.5-43$.

Blumenberg, E., \& Shiki, K. (2004). Spatial mismatch outside of large urban areas: an analysis of welfare recipients in Fresno County, California. Environment and Planning C: Government and Policy, 118, 401421.

Brown, L. A., \& Chung, S. Y. (2006). Spatial segregation, segregation indices and the geographical perspective. Population Space and Place, 12(2), 125143 .

Bryden, J., \& Bollman, R. (2000). Rural employment in industrialized countries. Agricultural Economics, 22, $185^{-197 .}$

Chi, G., \& Zhu, J. (2008). Spatial regression models 
for demographic analysis. Population Research and Policy Review, 27(1), 17-42.

Cortese, C. F., Falk, R. F., \& Cohen, J. K. (1976). Further considerations on methodological analysis of segregation indexes American Sociological Review, $41(4), 630-637$.

Duncan, O. D., \& Duncan, B. (1955). A methodological analysis of segregation indices. American Sociological Review, 2O(2), 210-217.

Fischer, C. S., Stockmayer, G., Stiles, J., \& Hout, M. (2004). Distinguishing the geographic levels and social dimensions of US metropolitan segregation, 1960-2000. Demography, 41(1), 37-59.

Foulkes, M., \& Schafft, K. A. (2010). The Impact of Migration on Poverty Concentrations in the United States, 1995\&\#x2013;2000. Rural Sociology, 75(1), 90-110.

Frey, W. H., \& Farley, R. (1996). Latino, Asian, and black segregation in US metropolitan areas: Are multiethnic metros different? Demography, 33(1), 3550.

Iceland, J., Goyette, K. A., Nelson, K. A., \& Chan, C. (2010). Racial and ethnic residential segregation and household structure: A research note. Social Science Research, 39(1), 39-47.

Jargowsky, P. A. (1996). Take the money and run: Economic segregation in U.S. metropolitan areas. American Sociological Review, 61, 984-998.

Jargowsky, P. A. (2003). Stunning progress, hidden problems: The dramatic decline of concentrated poverty in the 1990s. Washington, DC: Brookings Institution.

Jargowsky, P. A., \& Kim, J. (2005). A Measure of Spatial Segregation: The Generalized Neighborhood Sorting Index. National Poverty Center Working Paper Series, 5(3).

Jensen, L., McLaughlin, D. K., \& Slack, T. (2003). Rural poverty: the persisting challenge. In D. L. Brown \& L. E. Swanson (Eds.), Challenges for rural America in the 21st century (pp. 118-134). University Park, PA: The Pennsylvania State University Press.

Johnson, K. M., \& Lichter, D. T. (2010). Growing
Diversity among America's Children and Youth: Spatial and Temporal Dimensions. Population \& Development Review, 36(1), 151-176.

Jolliffe, D. (2004). Rural poverty at a glance. Rural Development Research Report, Number 100, Washington, DC: Economic Research Service, United States Department of Agriculture.

Kandel, W. (2005). Rural Hispanics at a Glance. Washington, DC: Economic Research Service, US Department of Agriculture,.

Kandel, W., \& Cromartie, J. (2004). New Patterns of Hispanic Settlement in Rural America. Washington, DC: Economic Research Service, U.S. Department of Agriculture.

Lichter, D. T., \& Brown, D. L. (2011). Rural America in an Urban Society: Changing Spatial and Social Boundaries. Annual Review of Sociology, 37, 565-592.

Lichter, D. T., \& Johnson, K. M. (2007). The Changing Spatial Concentration of America's Rural Poor

Population. Rural Sociology, 72(3), 331-358.

Lichter, D. T., Parisi, D., Grice, S. M., \& Taquino, M. C. (2007). National estimates of racial segregation in rural and small-town America. Demography, 44(3), 563-581.

Lichter, D. T., Parisi, D., Taquino, M. C., \& Beaulieu, B. (2008). Race and the micro-scale spatial concentration of poverty. Cambridge Journal of Regions, Economy and Society, 1, 51-67.

Lobao, L. M., Hooks, G., \& Tickamyer, A. R. (Eds.). (2007). The Sociology of Spatial Inequality. Albany, NY: State University of New York Press.

Logan, J. R., Alba, R. D., \& Zhang, W. Q. (2002). Immigrant enclaves and ethnic communities in New York and Los Angeles. American Sociological Review, 67(2), 299-322.

Logan, J. R., Stults, B. J., \& Farley, R. (2004). Segregation of minorities in the metropolis: Two decades of change. Demography, 41(1), 1-22.

MacKay, R. R. (2003). Twenty-five years of regional development. Regional Studies, 37, 303-317. 
Massey, D. S. (1996). The Age of Extremes:

Concentrated Affluence and Poverty in the Twenty-

First Century. Demography, 33(4), 395-412.

Massey, D. S., \& Denton, N. A. (1988). The dimensions of residential segregation. Social Forces, 67(2), 281315 .

Massey, D. S., \& Denton, N. A. (1989). Hypersegregation in U.S. Metropolitan Areas: Black and Hispanic Segregation along Five Dimensions. Demography, 26(3), 373-391.

Massey, D. S., White, M. J., \& Phua, V. C. (1996). The dimensions of segregation revisited. Sociological Methods \& Research, 25(2), 172-206.

Partridge, M. D., \& Rickman, D. S. (2008). Placebased policy and rural poverty: insights from the urban spatial mismatch literature. Cambridge $J$ Regions Econ Soc, 1(1), 131-156.

R Development Core Team (2012). R: A language and environment for statistical computing (Version 2.15.1). Vienna, Austria: R Foundation for Statistical Computing.

Tickamyer, A. R., \& Duncan, C. M. (1990). Poverty and Opportunity Structure in Rural America. Annual
Review of Sociology, 16(1), 67-86.

Tiefelsdorf, M., \& Griffith, D. (1999). A variancestabilizing coding scheme for spatial link matrices. Environment and Planning A, 31, 165-180.

Vias, A. C. (2012). Perspectives on U.S. rural labor markets in the first decade of the twenty-first century. In L. j. Kulcsar \& K. J. Curtis (Eds.), International Handbook of Rural Demography (pp. 273-291). New York: Springer.

Voss, P. R., Long, D. D., Hammer, R. B., \& Friedman, S. (2006). County child poverty rates in the US: a spatial regression approach. Population Research and Policy Review, 25(4), 369-391.

Wilkes, R., \& Iceland, J. (2004). Hypersegregation in the twenty-first century. Demography, 41(1), 23-36.

\section{Declaration of Conflicting Interests}

The author declared no potential conflicts of interest with respect to the research, authorship, and/or publication of this article. 